\title{
Social communication and functional independence of the elderly in a community assisted by the family health strategy
}

Angelina Travassos de Queiróz Coutinho(1) Mirella Bezerra Rodrigues Vilela(1) Maria Luiza Lopes Timóteo de Lima(1)

Vanessa de Lima Silva ${ }^{(1)}$

(1) Universidade Federal de Pernambuco UFPE, Recife, Pernambuco, Brasil. Research support source: Conselho Nacional de Pesquisa (CNPQ), process number 461373/2014-9.

Conflict of interests: Nonexistent

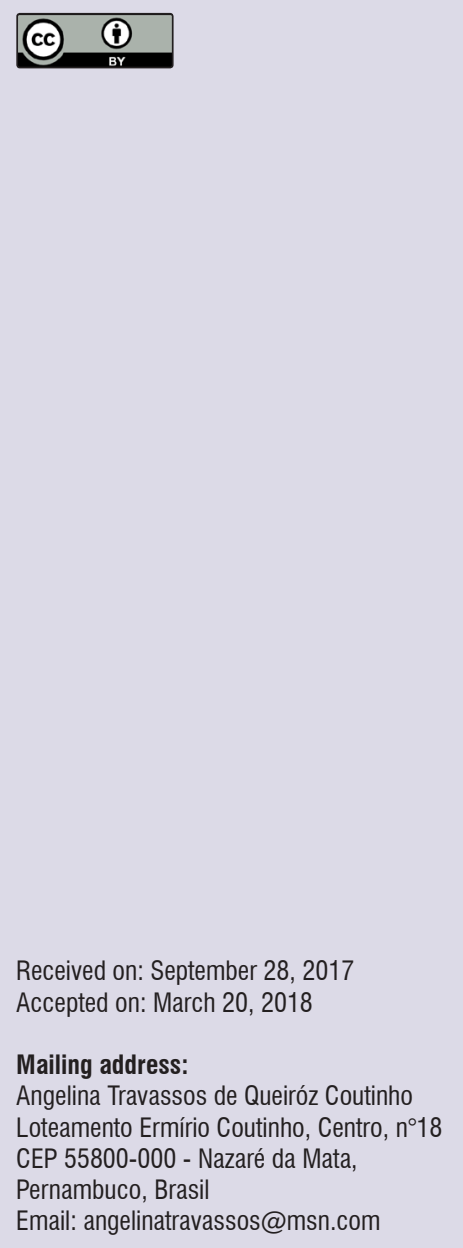

\section{ABSTRACT}

Purpose: to analyze the association between social communication and independence for the Daily Living Instrumental Activities of elderly people residing in a territory assisted by the Family Health Strategy.

Methods: a sectional study was conducted, with elderly $\geq 60$ years. Data collection was performed through the application of a socioeconomic and demographic questionnaire and protocols for the evaluation of functional independence and social communication. Functional independence was assessed through the scale of instrumental activities of daily living; And the media, through the media domain of the ASHA FACTS protocol. Data were analyzed through descriptive statistics and logistic regression.

Results: 123 elderly, in the average age of 68 years (Standard Deviation $=7$ years), the majority being females $(72,4 \%)$ and dependent $(64,2 \%)$, were evaluated. Most elderly with insufficient social communication had functional dependence (70,9\%). After control by sociodemographic variables, the social communication remained significantly associated with the functional dependency for the instrumental activities of everyday life (Odds Ratio $=2.45 ; p=0.04$ ).

Conclusion: elderly people presented with insufficient communication show twice as much the chance of having functional dependence for the Daily Living Instrumental Activities scale, as compared to elderly people with sufficient social communication. Knowledge of such an association can contribute to improving the care and quality of life of this population.

Keywords: Elderly; Communication; Speech, Language and Hearing Sciences; Dependency; Family Health 


\section{INTRODUCTION}

Active aging can be defined as the process of optimization of the opportunities of health, participation and security, with the purpose of improving the quality of life of people as they age. Therefore, any social or health policy intended for the elderly population must take into consideration the promotion of healthiness and the maintenance of the functional capability. The functional capability is related to the combination between the individual and the environment in which they live; it can be defined as health-related abilities, which allow the person to be and do what is important to themselves ${ }^{1-3}$.

An older person is considered active when they are capable of performing daily life activities by themselves, independently and autonomously, despite eventual diseases. Therefore, the independence refers to the capability of performing something in their own way. It means execution, and it depends directly on mobility and communication, so that the elder's health is defined by the harmonious operation of four functional domains: cognition, humor, mobility and communication ${ }^{4}$

With aging comes countless physiological changes and the increase of chronic conditions. At the age of 60 , the main causes of disabilities and death come from vision, hearing and movement impairments and non-communicable diseases (NCD), including cardiovascular and respiratory diseases, stroke, cancer and dementia. NCDs are the main cause of death of this population in Brazil and worlwide ${ }^{3-5}$.

Difficulties to communicate, which may also be due to DNCs, are very common in the elderly population; in many cases, the loss of cognitive functions may be related to the lifestyle. The aging process is directly related to the life experiences of each person; these experiences constitute and are constituted by the psychosocial, biological, physic and cultural environments that are experienced by the person who ages ${ }^{6}$.

The isolation of an elderly person, many times related to the younger society and the decrease in the quality of their communication, may generate a profound psychosocial impact on the elder. Because of that, it is necessary to highlight that the healthiness of communication is an important determinant for active aging, given that it allows the elder's inclusion and social interaction, preventing isolation and depressive disorders ${ }^{7}$.

Language is one of the fundamental aspects of an individual's life. It is directly involved in the way people communicate and perform their social roles, which is why language is considered of extreme importance for the improvement of the quality of life of the population ${ }^{8}$.

Through this perspective, the incentive for the health of communication, corpus of Speech-language Pathology (SLP), provides important benefits for the social inclusion of the elder. Social communication can be defined as the synergy of social interaction, social cognition, pragmatics (verbal and nonverbal) and of the processing of receptive and expressive language ${ }^{9}$.

Communication is the link between isolation and social activity. It is through speech, hearing and language that inclusion happens. Speech-language pathology has an important role on the aging process because it deals with human communication, through the stimulus to the development of language ${ }^{7}$.

Knowing the links between social communication and elder independence may contribute to the enrichment of SLP and gerontological literature, considering the incipient scientific publications on this field, as well as to the development of public policies in elder healthcare.

This study aimed to analyze the association between social communication and independence on instrumental activities of daily living (IADLs) in elderly residents inside a territory covered by the Family Health Strategy in the municipality of Recife-PE.

\section{METHODS}

This is a cross-sectional study, approved by the Committee of Ethics in Research of the Federal University of Pernambuco - UFPE under the protocol 1.172.962. The study population comprised 123 elderly, over 60 years old, residents of a zone covered by a family health team belonging to the $4^{\text {th }}$ Sanitary District of the Municipality of Recife, Pernambuco, characterized as an area of social vulnerability. Elderly that presented any morbidity conditions that affect their physical and/or cognitive capabilities were excluded.

Data collection was conducted through interviews with the elderly and their caretakers, as well as through surveys applied to the group of seniors. The interview was composed by a socioeconomic and pre-structured demographic questionnaire containing the following variables: gender, age, marital status, race/color, literacy and family income, coupled with evaluation tests of the IADLs and the Functional Assessment of Communication Abilities - ASHA FACTS. The elder's family members and the referenced community health agents were labeled as caretakers. The community health agent was considered a caretaker in situations 
in which the elder was alone, or which the closest person did not provide the necessary information to be collected, making the health agent the closest person that assesses the elder systematically. Data collection was conducted inside the elder's residence, after the identification of their address, registered at the family health unit. Following the explanation about the research and the agreement of both elder and caretaker, Free and Clarified Terms of Consent were signed.

The data collection protocol comprises personal data, measures of functional independence and factors related to the healthiness of human communication. It is important to stress that the questionnaires applied on the research were culturally adapted and validated to the Brazilian population. The questionnaire ASHA FACTS (Annex A) was used to characterize the elderly' communication skills. The questionnaire is a basic instrument of assessment of the communicative abilities in the individual's natural environment, considering compensations, adaptations and the necessary time to communicate. It was designed to be answered by the caretaker from the reference to the elder, and the same criterion was used in this study.

The questionnaire was validated to Portuguese by Carvalho ${ }^{10}$, and applied to healthy elderly by Garcia and Mansur ${ }^{11}$. It is composed by 43 items divided into four domains: 21 items about social communication, 7 items of communication of basic needs, 10 items of reading, writing and numerical concepts and 5 items of daily planning. The questionnaire provides quantitative information in a scale that varies from 1 to 7 points ( 7 being the grade for an individual that does not need help to perform the activity, while 1 is given when the need of aid is maximum). After the application of the questionnaire, it was possible to verify the communicative independence of the individual. For this study only the domain of social communication was analyzed, which assesses social situations that demand interaction with the speaker.

The IADLs were identified using the Lawton and Brody Scale, adapted by Freitas and Miranda ${ }^{12}$. According to the presented degree of limitation for the performance of IADLs it is possible to determine if an elder is or not capable of maintaining an independent life. The test was applied only with the elder and aimed to evaluate their functional performance in terms of IADLs that allow them to keep an independent life.

The elderly are ranked as independent or dependent regarding the performance of nine functions. For each question, the first answer means dependence; the second, partial dependence or aided capacity; and the third, dependence. The lowest score is 9 and the highest is 27 points. The score is useful for keeping record of the older person, based on evolutionary comparison. Questions 4 to 7 varied according to gender and were adapted to activities such as climbing up stairs and gardening.

This study used the independence on IADLs as outcome variable, and it intended to analyze its association to the elderly' social communication, to the control of the sociodemographic variables: age, gender, marital status, race/color, literacy and family income.

To analyze the functional dependence, assessed using the Lawton Scale, elderly that obtained score from 9 to 26 were considered dependent; those who obtained 27 points were considered independent.

Concerning the analysis of social communication, this research used the score from the domain social communication from the ASHA FACTS protocol. Elderly whose score varied from 1,0 to 6,99 were considered with insufficient social communication; elderly who scored 7,0 were considered with sufficient social communication.

The data were analyzed by the software Epilnfo 3.5.1. The analysis of the association between the response variable and the other variables was made using Pearson's chi-squared test and Fisher's exact test, considering a $5 \%$ statistical significance level.

The multivariate logistic reversion model, with $a=$ $5 \%$, was used to estimate the chance of social communication affecting independence on IADLs. Before applying the model, univariate analyses between the independent variables and social communication were conducted to determine which variables would form the model. For the model, the elected variables were the ones that in the analysis obtained a $p$-value $<0,25^{13}$, using the Backward method, with $a=5 \%$.

\section{RESULTS}

One hundred and twenty-three individuals participated in the study. The average age of the studied population was 68 years (Standard Deviation (SD) $=7$ years) and $63.4 \%$ of the population are aged between 60-69 years. Of these, $54.4 \%$ presented themselves as dependent and $79.5 \%$ as independent. Comparing the groups, age was the only variable that presented a statistically significant difference $(p<0.01)$. 
Of the participating elderly, $72.4 \%$ were female, the female majority was kept among the assessed groups, representing $77.2 \%$ of the dependent elderly and $63,6 \%$ of the independent ones. Regarding marital status, $35.4 \%$ of the dependent individuals are widowed and $27.8 \%$ are married; a higher percentage of married (40.9\%) and widowed (31.8\%) individuals was found among the independent elderly. Concerning the variable race/color, $69 . \%$ of the dependent elderly were of mixed ethnicity, while $56,8 \%$ of those were independent.

Regarding the analysis of socioeconomic variables, it was observed that most of the studied older population is literate; however, when analyzing the differences by level of functional dependence, a statistically significant difference was found between the groups. Among the dependent older people, 50,6\% are illiterate. This proportion falls back to $22.7 \%$ among independent individuals, indicating some influence of literacy on the elderly' functional independence. Most of the elderly's family income is of up to a minimum wage, representing $77.2 \%$ of the dependent elderly and $68.2 \%$ of the independent ones (Table 1).

When analyzing dependence on IADLs, most of them presented themselves as dependent, representing $64.2 \%$ of the total number of assessed elderly (Table 2).
In the comparative analysis between the state of social communication and functional dependence on IADLs, $70.9 \%$ of the elderly with insufficient social communication presented dependence, while $52.3 \%$ of the older individuals with sufficient social communication presented dependence. This demonstrates some influence of communication on the participating elderly' functionality (Table 3).

After the control by age, gender, marital status, race/color, literacy and family income, social communication maintained a significant association with functional dependence on IADLs, indicating that elderly with insufficient social communication present more than twice the odds (odds ratio, $O R=2.25$; $p=0.04$ ) of developing functional dependence on IADLs when compared with elderly with sufficient social communication. In the final model of multivariate analysis, the variables age, gender and literacy remained as factors associated to functional dependence on IADLs. Individuals older than 70 years presented three times more chance $(O R=3.75 ; p<0.01)$ of being dependent when compared with the younger group. Moreover, older women presented almost three times (OR = 2.78; $p=0.03$ ) more chances of being dependent in comparison to men, and illiterate elderly presented 2.69 times $(p=0.03)$ more chance of being dependent when compared to literate elderly (Table 4). 
Table 1. Distribution of dependent and independent elderly according to demographic and socioeconomic factors, Recife, 2016

\begin{tabular}{|c|c|c|c|c|c|c|c|c|}
\hline \multirow{2}{*}{ VARIABLES } & \multicolumn{2}{|c|}{ DEPENDENT ELDERLY } & \multicolumn{2}{|c|}{ INDEPENDENT ELDERLY } & \multicolumn{2}{|c|}{ TOTAL } & \multirow{2}{*}{$\mathrm{X}^{2}$ * } & \multirow{2}{*}{ P VALUE } \\
\hline & $\mathrm{N}$ & $\%$ & $\mathrm{~N}$ & $\%$ & $\mathrm{~N}$ & $\%$ & & \\
\hline \multicolumn{9}{|l|}{ AGE } \\
\hline 60 to 69 years & 43 & 54.4 & 35 & 79.5 & 78 & 63.4 & \multirow{3}{*}{9.12} & \multirow{3}{*}{$<0.01$} \\
\hline 70 to 79 years & 29 & 36.7 & 9 & 20.5 & 38 & 30.9 & & \\
\hline 80 years and over & 7 & 8.9 & 0 & 0 & 7 & 5.7 & & \\
\hline \multicolumn{9}{|l|}{ GENDER } \\
\hline Males & 18 & 22.8 & 16 & 36.4 & 34 & 27.6 & \multirow{2}{*}{1.97} & \multirow{2}{*}{0.16} \\
\hline Females & 61 & 77.2 & 28 & 63.6 & 89 & 72.4 & & \\
\hline \multicolumn{9}{|l|}{ MARITAL STATUS } \\
\hline Married & 22 & 27.8 & 18 & 40.9 & 40 & 32.5 & \multirow{5}{*}{3.07} & \multirow{5}{*}{0.54} \\
\hline Legally separated & 5 & 6.3 & 3 & 6.8 & 8 & 6.5 & & \\
\hline Divorced & 10 & 12.7 & 5 & 11.4 & 15 & 12.2 & & \\
\hline Widowed & 28 & 35.4 & 14 & 31.8 & 42 & 34.1 & & \\
\hline Single & 14 & 17.7 & 4 & 9.1 & 18 & 14.6 & & \\
\hline \multicolumn{9}{|l|}{ RACE/COLOR } \\
\hline White & 12 & 15.2 & 11 & 25 & 23 & 18.7 & \multirow{5}{*}{5.95} & \multirow{5}{*}{0.20} \\
\hline Black & 9 & 11.4 & 5 & 11.4 & 14 & 11.4 & & \\
\hline Mixed & 55 & 69.6 & 25 & 56.8 & 80 & 65 & & \\
\hline Yellow & 3 & 3.8 & 1 & 2.3 & 4 & 3.3 & & \\
\hline Native American & 0 & 0 & 2 & 4.5 & 2 & 1.6 & & \\
\hline \multicolumn{9}{|l|}{ LITERACY } \\
\hline Literate & 39 & 49.4 & 34 & 77.3 & 73 & 59.3 & \multirow{2}{*}{8.00} & \multirow{2}{*}{$>0.01$} \\
\hline Illiterate & 40 & 50.6 & 10 & 22.7 & 50 & 40.7 & & \\
\hline \multicolumn{9}{|l|}{ FAMILY INCOME } \\
\hline 0 to $1 \mathrm{MW}^{* *}$ & 61 & 77.2 & 30 & 68.2 & 91 & 74 & \multirow{3}{*}{2.97} & \multirow{3}{*}{0.23} \\
\hline 1,1 to $2 \mathrm{MW}$ & 16 & 20.3 & 14 & 31.8 & 30 & 24.4 & & \\
\hline 2,1 to $5 \mathrm{MW}$ & 2 & 2.5 & 0 & 0 & 2 & 1.6 & & \\
\hline TOTAL & 79 & 100 & 44 & 100 & 123 & 100 & & \\
\hline
\end{tabular}

* Pearson's chi-squared test with $\alpha=5 \%$.

** Minimum Wage.

Table 2. Distribution of elderly according to dependence on instrumental activities of daily living, Recife, 2016

\begin{tabular}{cccc}
\hline DEPENDENCE ON IADLs* & N & $\%$ & Cl $^{* *}$ (95\%) \\
\hline Dependent & 79 & 64.20 & $55.10 \%$ a $72.70 \%$ \\
Independent & 44 & 35.80 & $27.30 \%$ a $44.90 \%$ \\
\hline TOTAL & 123 & 100.00 & - \\
\hline
\end{tabular}

* Instrumental Activities of Daily Living.

** Confidence interval. 
Table 3. Distribution of dependent and independent elderly according to social communication score, Recife, 2016

\begin{tabular}{ccccccccc}
\hline SOCIAL & \multicolumn{2}{c}{ DEPENDENT ELDERLY } & \multicolumn{1}{l}{ INDEPENDENT ELDERLY } & \multicolumn{2}{c}{ TOTAL } & \multirow{2}{*}{ 2 * } & \multirow{2}{*}{ P VALUE } \\
\cline { 2 - 8 } COMMUNICATION & $\mathbf{N}$ & $\%$ & $\mathbf{N}$ & $\%$ & $\mathbf{N}$ & $\%$ & & \\
\hline Insufficient & 56 & 70.9 & 21 & 47.7 & 77 & 62.6 & \multirow{2}{*}{5.52} & \multirow{2}{*}{$\mathbf{0 . 0 2}$} \\
Sufficient & 23 & 29.1 & 23 & 52.3 & 46 & 37.4 & & \\
\hline TOTAL & 79 & 100 & 44 & 100 & 123 & 100 & & \\
\hline
\end{tabular}

* Pearson's chi-squared test with $\alpha=5 \%$.

Table 4. Results of univariate and multivariate analyses of the association between social communication and functional independence among elderly, Recife, 2016

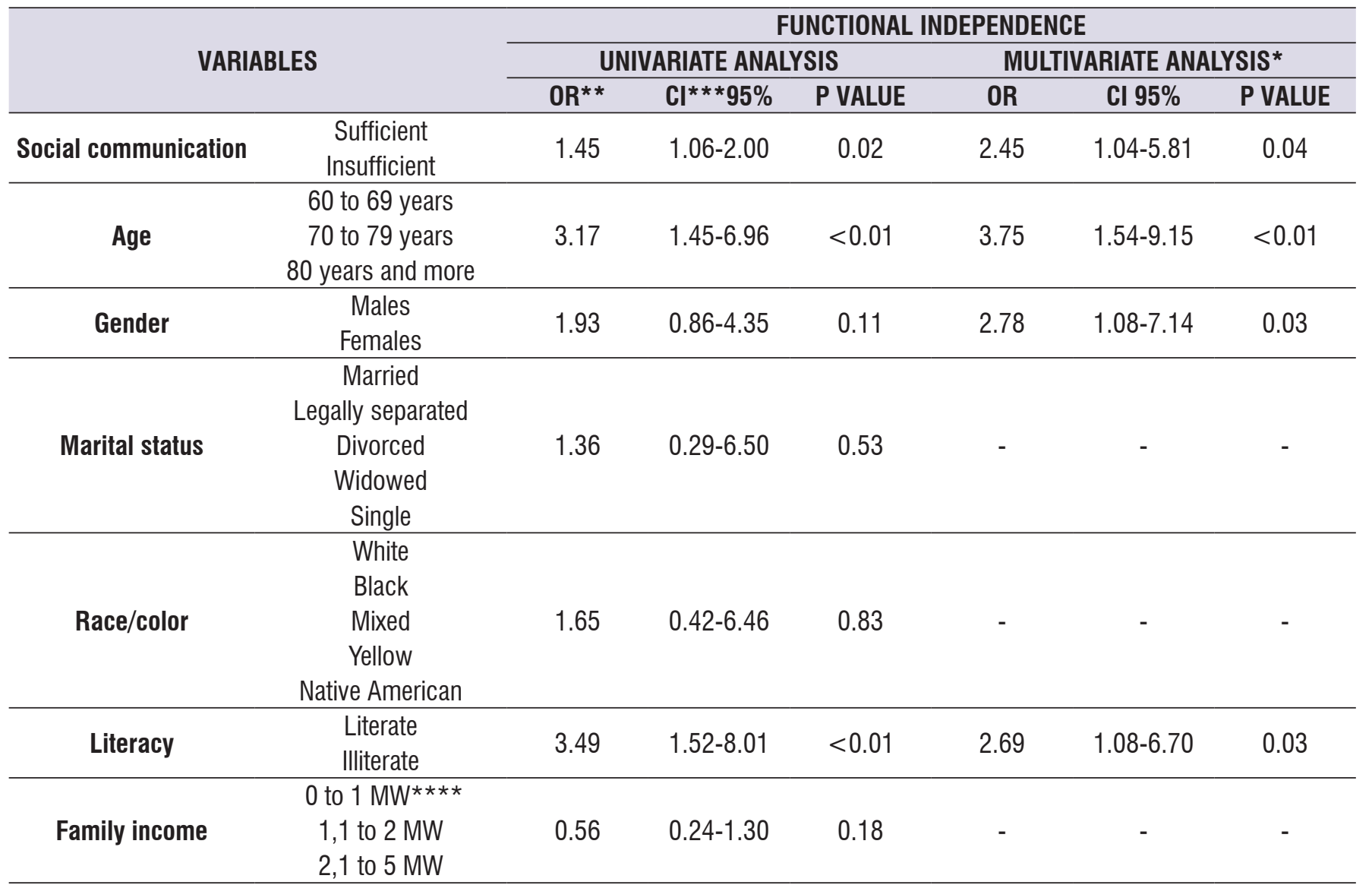

* Multivariate Logistic Regression Model.

** Odds Ratio.

$\star * *$ Confidence Interval.

$\star \star \star \star$ Minimum wage 


\section{DISCUSSION}

The studied population presented a high proportion of younger elderly, corroborating other researches, such as the study performed by Albuquerque et al. ${ }^{14}$, which found a similar prevalence $(60 \%)$ of younger elderly at the municipality of Recife-PE. This can be explained by the still low longevity of the older population that resides in developing nations ${ }^{15}$.

In developing countries, including Brazil, demographic transition happens unattached to social development and in an accelerated rhythm. Therefore, a higher number of people live longer, with a greater number of chronic conditions nonetheless, which may result in different degrees of functional incapability ${ }^{16,17}$.

When analyzing dependence on IADLs, most of the elderly presented themselves as dependent, a similar result to the study produced by Freitas et al. ${ }^{18}$. This may happen due to the functional decrease, since older people present a higher probability of developing dependence when compared to younger individuals because, as years go by, incapacitating chronic conditions appear, which make the elderly more dependent on aid ${ }^{19}$.

In this study, a higher percentage was found for females, with an approximate result to the national territory, given the fact, that for the elderly' ratio, the indicator was of 80 men for 100 women in this age group. Similar studies ${ }^{18,20}$ have also showed that the percentage of older women is higher than that of men. Women's life expectancy is higher than men's; this happens because of a higher exposure to risk factors at work as well as violent deaths (murders and work accidents), whose victims are mostly men. This characteristic of the older population also happens due to the fact that women are warier of symptoms, and they also use healthcare services more often than men ${ }^{21}$.

In the present study, $40 \%$ of the population is illiterate, a finding that resembles another study that was also produced on the Brazilian Northeast region. Among the illiterate elderly, most of them were considered dependent, presenting a statistically significant difference, which may may mean that the level of education is associated to functional independence. The decrease of communicative skills on aging is boosted in less educated individuals, who develop less functional strategies to compensate the effects of loss $^{11}$.

Moreover, it was observed that most of the studied population has a family income of up to one minimal wage, which may also indicate a relation with functional dependence. In the United States of America and in England, it is shown that disparities by income and/ or education on the older population's functional capability has increased over the last decades ${ }^{22}$.

Most of the dependent elderly are widowed, and most of the independent individuals are married. This finding demonstrates that living with a partner may bring more security and benefits to older citizens' health ${ }^{14}$.

Regarding the prevalence of the variable race/ color, the Brazilian National Household Sample Survey (PNAD) reveals that people of mixed ethnicity represents $43,7 \%$ of the country's total population. In this way, it can be explained the prevalence of mixed ethnicity elderly in this study ${ }^{23}$.

Concerning communication, it is perceived that the reduction of sensory-perceptive capabilities, which occur during the aging process, may influence the communication of older people. Such changes are perceived through the reduction of the capability of receiving and processing information that comes from the environment ${ }^{24}$.

Communication is the ability of establishing a productive relationship with the environment, and it depends on seeing, hearing and speaking. The loss of these functions results in the great geriatric syndromes, such as: cognitive incapacity, posture instability, immobility and communicative incapacity. This last syndrome may be considered an important cause of loss or restriction of the social participation (functionality), thus compromising the capacity of executing decisions, directly affecting the individual's independence ${ }^{4}$.

In the present study it was observed that the social communication factor was kept in significant association with functional dependence on IADLs after the control of variables, indicating that elderly with insufficient social communication presented higher chance of having functional dependence on IADLs. For the elder, autonomy and independence are related to the ability of actively performing social activities; for that to happen, communication becomes a fundamental part of the process ${ }^{25}$.

On the final model of multivariate analysis, the variables age, gender and literacy remained as the associated factors to functional dependence on IADLs. Regarding age, this study identified that people over 70 years of age were three times more likely of being dependent, when compared to the younger group. The relation with age is corroborated by another study 
produced on the Brazilian Northeast region ${ }^{26}$. This finding may be explained by the characteristics of aging, since physical and organic limitations inherent to this process influence the physical, intellectual and social functions ${ }^{26}$.

In this study it was also observed that older women presented more likeliness of being dependent when compared to men. National and international studies have presented the same result regarding this prevalence ${ }^{27,28}$. This finding reinforces the premise that aging, for being a phenomenon with a great component of femininity, favors older women, more likely of being functionally dependent ${ }^{29}$.

Illiterate elderly, on their turn, presented higher chances of being dependent when compared to literate ones. This finding is presented in a similar way in a study produced on the Brazilian Northeast region, in which $63.25 \%$ of the elderly are illiterate ${ }^{30}$.

When interpreting the results of this study, it is important to register the limitation concerning the sectional design, which renders impossible the identification of the temporality of the phenomena, thus not allowing the inference of the relation of causality between such variables.

We suggest the production of new studies with broader samples and other epidemiological designs, such as longitudinal studies, for a better understanding of the relation between the elder's communication and functionality, a topic still little explored on scientific literature. Such findings hold the potential of strengthening speech-language pathology with older populations, as well as the interprofessional care, with the support of speech-language pathology, and the development of actions promoting the elderly' social communication.

Moreover, it is important to highlight the stimulus towards social communication actions on the development of public policies that attend to the intrinsic needs of aging, given that this population presents higher prevalence of incapacities, creating new challenges for the social and health systems.

\section{CONCLUSION}

The results here found demonstrate that elderly with insufficient social communication are more than twice more likely to present functional dependence on IADLs, when comparing with elderly with sufficient social communication, which means that social communication is related to functional independence on IADLs on the studied elderly population.
The identification of this association in this study may provide important indicators for the targeting of speechlanguage pathology actions with older individuals, especially on the context of primary healthcare, aiming on the well-being and the improvement of quality of life of this population regarding aspects related to communication.

\section{ACKNOWLEGDEMENTS}

To the elderly, for their availability in participating on the research. To the research group for participating on the data collection and to the community health agents for their support given at all the interviews.

\section{REFERENCES}

1. World Health Organization. Envelhecimento ativo: uma política de saúde. 4 ed. Brasília: Organização Pan-Americana da Saúde; 2005.

2. Veras RP. International experiences and trends in health care models for the elderly. Ciênc. saúde coletiva. 2012;17(1):231-8.

3. World Health Organization. World report on ageing and health. [cited 2016 Dez 05]. Available from: http://apps.who.int/iris/bitstream/10665/186463/1/9 789240694811_eng.pdf?ua=1.

4. Moraes EN, Marino MCA, Santos RR. Main geriatric syndromes. Rev Med Minas Gerais. 2010;20(1):54-66.

5. Duncan B, Chor D, Aquino EML, Bensenor IM, Mill JG, Schmidt MI et al. Chronic non-communicable Diseases in Brazil: priorities for disease management and research. Rev Saúde Pública. 2012;46(Supl):126-34.

6. Costa MLG, Costa EG. Envelhecimento, comunicação e suas relações. In: Marchesan IQ (org). Desenvolvimento da comunicação humana nos diferentes ciclos de vida. Barueri (SP): Pró Fono; 2015. p. 213-27.

7. Silva VL, Silva DM, Amaral AKFJ, Albuquerque AG, Oliveira GSM, Barros PML et al. A promoção da saúde do idoso na perspectiva da Fonoaudiologia. In: Vasconcelos BCE, Silva HJ, Lima MLLT, Vilela MBR, Silva VL (Org). A Prática Fonoaudiológica na Atenção Primária à Saúde. São José do Campos (SP): Pulso Editorial; 2013. p. 165-76.

8. Santiago LM, Graça CML, Rodrigues MCO, Santos GB. Characterization of the elderly health in a speech and language therapy perspective. Rev. CEFAC. 2016;18(5):1088-96. 
9. Adams C. Social communication intervention for school-age children: rationale and description. Seminars in Speech and Language. 2005;26(3):181-8.

10. Carvalho IAM. Avaliação Funcional das Habilidades de Comunicação - ASHA FACS para população com doença de Alzheimer [dissertação]. São Paulo (SP): Faculdade de Medicina da Universidade de São Paulo; 2006.

11. Garcia FHA, Mansur LL. Functional communication assessment: the healthy elderly. Acta Fisiatr. 2006;13(2):87-9.

12. Freitas EV, Miranda RD. Parâmetros clínicos do envelhecimento e avaliação geriátrica ampla. In: Freitas EV, Py L (Org). Tratado de Geriatria e Gerontologia. 2a ed. Rio de Janeiro (RJ): Guanabara-Koogan; 2006. p. 900-9.

13. Hosmer DW, Lemeshow S. Applied logistic regression. 2th ed. New York: John Wiley and Sons; 2000.

14. Albuquerque AG, Oliveira GSM, Silva VL, Nascimento CB. Functional ability and language of participant and non-participant elderly in groups of multidisciplinary intervention in primary health care. Rev. CEFAC. 2012;14(5):952-62.

15. Huisman M, Kunst AE, Andersen O, Bopp M, Borgan JK, Borrell C. Socioeconomic inequalities in mortality among elderly people in 11 european populations. J Epidemiol Community Health. 2004;58(6):468-75.

16. Kalache A. The world is ageing: a pact of social solidarity is an imperative. Cien Saude Coletiva. 2008;13(4):1107-11.

17. Alves LC, Leite IC, Machado CJ. The concept and measurement of functional disability in the elderly population: a literature review. Cienc Saude Coletiva. 2008;13(4):1199-207.

18. Freitas RS, Fernandes MH, Coqueiro RS, Reis Júnior WM, Rocha SV, Brito TA. Functional capacity and associated factors in the elderly: a population study. Acta Paul Enferm. 2012;25(6):933-9.

19. Santos AA, Pavarini SCl. Functionality of elderly people with cognitive impairments in different contexts of social vulnerability. Acta Paul Enferm. 2011;24(4):520-6.

20. Porciúncula RCR, Carvalho EF, Barreto KML, Leite VMM. Socio-epidemiological profile and autonomy of elderly in the city of Recife, northeastern Brazil. Rev. Bras. Geriatr. Gerontol. 2014;17(2):315-25.
21. Veras RP, Ramos LR, Kalache A. Crescimento da população idosa no Brasil: transformações e consequências na sociedade. Rev Saúde Pública. 1987;21(3):225-33.

22. Martin LG, Schoeni RF, Andreski PM, Jagger C. Trends and inequalities in late-life health and functioning in England. J Epidemiol Community Health. 2012;66(10):874-80.

23. Instituto Brasileiro de Geografia e Estatística. Diretoria de Pesquisas. Coordenação de Trabalho e Rendimento. Pesquisa Nacional por Amostra de Domicílios: Síntese dos Indicadores 2011. Rio de Janeiro: 2012. [Citado em: 2017 maio 29]. Disponível em: https://biblioteca.ibge.gov.br/ visualizacao/livros/liv61566.pdf.

24. Ministério da Saúde. Secretaria de Atenção à Saúde. Departamento de Atenção Básica. Envelhecimento e saúde da pessoa idosa. Cadernos de Atenção Básica. N. 19. Série A. Normas e Manuais Técnicos, Brasília, 2006.

25. Sobral AIGP. Comunicação e realização de atividades instrumentais de vida diária em idosos com comprometimento cognitivo leve. [Dissertação] Recife (PE): Universidade Federal de Pernambuco; 2015.

26. Maciel ACC, Guerra RO. Influence of biopsychosocial factors on the functional capacity of the elderly living in Brazil's Northeast. Rev. Bras. Epidemiol. 2007;10(2):178-89.

27. Palacios-Ceña $D$, Jiménez-García R, Hernández Barrera V, Alonso-Blanco C, Carrasco-Garrido P, Fernández-de-Las-Peñas $\mathrm{C}$. Has the prevalence of disability increased over the past decade (20002007) in elderly people? A spanish populationbased survey. Journal of the American Medical Directors Association. 2012;13(2):136-42.

28. Barbosa BR, Almeida JM, Barbosa MR, RossiBarbosa LAR. Evaluation of the functional capacity of the elderly and factors associated with disability. Ciênc Saúde Coletiva. 2014;19(8):3317-25.

29. Junior EPP, Silva IT, Vilela ABA, Casotti CA, Pinto FJM, Silva MGC. Functional dependency and associated factor in elderly living with relatives. Cad. Saúde Colet. 2016;24(4):404-12.

30. Vilela ABA, Meira EC, Souza AS, Cardoso IS, Silva EL, Takase LH. Profile of family caregivers for ill and/or frail elderly people in the sociocultural context of Jequié-BA. Rev. Bras. Geriatr. Gerontol. 2006;9(1):55-69. 


\section{ANNEX A}

\section{ASHA FACTS - Measures of communication independence \\ Social communication in situation of opportunity}

\begin{tabular}{|c|c|c|c|c|c|c|c|c|}
\hline $\begin{array}{l}\text { SOCIAL COMMUNICATION } \\
\text { In situation of opportunity }\end{array}$ & 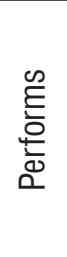 & 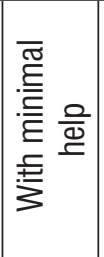 & 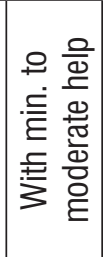 & 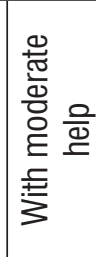 & 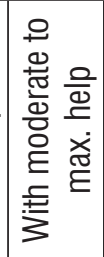 & 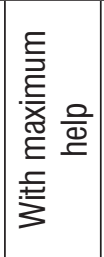 & 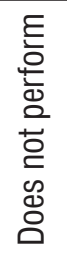 & 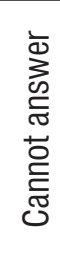 \\
\hline 1. Refer to family members by name? (e.g. family, friends and colleagues) & 7 & 6 & 5 & 4 & 3 & 2 & 1 & $\mathrm{~N}$ \\
\hline $\begin{array}{l}\text { 2. Ask for information about people or happenings? (e.g. "What is on the } \\
\text { TV? Where do you live?") }\end{array}$ & 7 & 6 & 5 & 4 & 3 & 2 & 1 & N \\
\hline 3. Explain how to make coffee or any other process? & 7 & 6 & 5 & 4 & 3 & 2 & 1 & $\mathrm{~N}$ \\
\hline 4. Express agreement and disagreement? & 7 & 6 & 5 & 4 & 3 & 2 & 1 & $\mathrm{~N}$ \\
\hline 5. Talk on the phone? (e.g. answer to questions, give information) & 7 & 6 & 5 & 4 & 3 & 2 & 1 & $\mathrm{~N}$ \\
\hline 6. Participate on group conversation? (e.g. family dinner) & 7 & 6 & 5 & 4 & 3 & 2 & 1 & $\mathrm{~N}$ \\
\hline 7. Answer to yes or no questions? (e.g. "Are you cold?") & 7 & 6 & 5 & 4 & 3 & 2 & 1 & $\mathrm{~N}$ \\
\hline 8. Follow simple verbal instructions? (e.g. get the mail) & 7 & 6 & 5 & 4 & 3 & 2 & 1 & $\mathrm{~N}$ \\
\hline $\begin{array}{l}\text { 9. Understand implicit impression? (e.g. "It's getting late", as a suggestion } \\
\text { that it is time to go) }\end{array}$ & 7 & 6 & 5 & 4 & 3 & 2 & 1 & N \\
\hline $\begin{array}{l}\text { 10. Laugh on well-humored commentaries? (e.g. "I'm like wine, the older, } \\
\text { the better") }\end{array}$ & 7 & 6 & 5 & 4 & 3 & 2 & 1 & N \\
\hline $\begin{array}{l}\text { 11. Understand double-meaning expressions or inferences? (e.g. "He has } \\
\text { a heart of gold") }\end{array}$ & 7 & 6 & 5 & 4 & 3 & 2 & 1 & N \\
\hline 12. Understand conversations on loud environments? (e.g. restaurant) & 7 & 6 & 5 & 4 & 3 & 2 & 1 & $\mathrm{~N}$ \\
\hline $\begin{array}{l}\text { 13. Understand what is watched on TV or listened to on the radio? (e.g. } \\
\text { news, soap opera, commercials) }\end{array}$ & 7 & 6 & 5 & 4 & 3 & 2 & 1 & $\mathrm{~N}$ \\
\hline 14. Understand facial expressions? & 7 & 6 & 5 & 4 & 3 & 2 & 1 & $\mathrm{~N}$ \\
\hline 15. Understand voice tones? (e.g. angry, sad, excited) & 7 & 6 & 5 & 4 & 3 & 2 & 1 & $\mathrm{~N}$ \\
\hline 16. Start conversations with people? & 7 & 6 & 5 & 4 & 3 & 2 & 1 & $\mathrm{~N}$ \\
\hline 17. Add new information to the conversation? & 7 & 6 & 5 & 4 & 3 & 2 & 1 & $\mathrm{~N}$ \\
\hline 18. Change the subject of the conversation? & 7 & 6 & 5 & 4 & 3 & 2 & 1 & $\mathrm{~N}$ \\
\hline 19. Can keep up a conversation when someone else changes the subject? & 7 & 6 & 5 & 4 & 3 & 2 & 1 & $\mathrm{~N}$ \\
\hline $\begin{array}{l}\text { 20. Recognize when someone makes a communication mistake? (e.g. } \\
\text { uses the wrong word or talks about an irrelevant topic) }\end{array}$ & 7 & 6 & 5 & 4 & 3 & 2 & 1 & $\mathrm{~N}$ \\
\hline 21. Correct your own communication mistakes? & 7 & 6 & 5 & 4 & 3 & 2 & 1 & $\mathrm{~N}$ \\
\hline
\end{tabular}

\begin{tabular}{|l|c|c|c|}
\hline \multicolumn{4}{|c|}{ Independência da comunicação } \\
\hline \multirow{2}{*}{$\begin{array}{l}\text { Social } \\
\text { communication }\end{array}$} & TOTAL Score & $\begin{array}{c}\text { Number of } \\
\text { assessed items }\end{array}$ & Average score \\
\cline { 2 - 4 } & & & \\
\hline
\end{tabular}

